\title{
Renal colic and urolithiasis practice patterns in Canada: a survey of Canadian Urological Association members
}

\author{
Raj Satkunasivam, MD; Melise Keays, MD; Kenneth T. Pace, MD, MSc, FRCSC
}

Division of Urology, St. Michael's Hospital, Keenan Research Institute, University of Toronto, Toronto, ON

Cite as: Can Urol Assoc J 2011;5(5):324-7; D01:10.5489/cuaj.10193

\section{Abstract}

Background: We describe the practice variability of CUA (Canadian Urological Association) members and factors which predict these patterns for common stone scenarios.

Methods: We asked 308 English- and 52 French-speaking CUA members to complete online surveys in their respective languages. We collected demographic information on fellowship training, shock wave lithotripsy (SWL) access, academic setting and whether they are at a hospital with regionalized surgical services. Respondents indicated their actual as well as ideal treatment for scenarios of renal, proximal and distal ureteric calculi.

Results: In total, 131 urologists responded (36\% response rate), all of whom treated urolithiasis. Of this number, $17 \%$ had endourology fellowship training, $76 \%$ had access to SWL, $42 \%$ were at an academic institution and $66 \%$ were at institutions with regionalized surgical services. Actual and ideal treatment modalities selected for symptomatic, distal and proximal ureteric stones (4, $8,14 \mathrm{~mm}$ ) were consistent with published guidelines. There were discrepancies between the use of ureteroscopy and SWL in actual versus ideal scenarios. Actual and ideal practices were congruent for proximal ureteric stones and asymptomatic renal calculi. In multivariate analysis, respondents were less likely to perform ureteroscopy on proximal 4- and 8-mm stones if they were at a hospital with regionalized surgical services (OR: $0.097 ; 95 \% \mathrm{Cl}$ : $0.01-0.76, p=0.03$ and OR: $0.330 ; 95 \% \mathrm{Cl}: 0.13-0.83, p=0.02$ ). Interpretation: There is clinical variability in the management of urolithiasis in Canada; however, management approaches fall within published guidelines. Type of hospital and access to operating room resources may affect treatment modality selection.

\section{Introduction}

There are a wide variety of modalities available to Canadian urologists who treat urolithiasis, ranging from observation, to shock wave lithotripsy (SWL), to ureteroscopy (URS) and to percutaneous nephrolithotomy (PCNL). In addition, tempo- rizing measures, such as ureteral stents or nephrostomy tubes, may be used prior to definitive management. Lastly, medical expulsive therapy (MET) using alpha-blockers is widely used. ${ }^{1}$ While published guidelines provide a framework for selecting the appropriate modality, there appears to be significant variation in the real-world utilization of these modalities. ${ }^{2-5}$

The choice of treatment modality for urolithiasis depends on multiple factors, including patient, stone and surgeon factors. The urologist evaluates patient and stone characteristics and weighs them with patient preferences and the efficacy and morbidity of the available treatments before recommending treatment. This complex decision-making process may result in one or more equally reasonable treatment options. The execution of treatment depends on several "real-world" factors, including a surgeon's training, access to technologies and operating room availability in the local environment of practice.

Herein we describe the practice patterns of members of the Canadian Urological Association (CUA) with respect to nephrolithiasis (intra-renal calculi), proximal ureteric and distal ureteric stones. We collected information on the actual pattern of treatment and urologists' opinion of the ideal treatment to identify discrepancies. Lastly, using multivariable logistic regression analysis, we sought to determine predictors of specific treatment modalities in actual practice.

\section{Materials and Methods}

We surveyed members of the CUA (308 English- and 52 French-speaking) between May and August 2009 using an online questionnaire (surveymonkey.com) available in both English and French. Members were invited to participate in the survey via e-mail by the administrative office of the CUA; 2 follow-up emails were sent at 2-week intervals. Participation was voluntary, without honorariums; results were blinded to the investigators and to the CUA administrative office. The online survey allowed only those indicating that they actively treat urolithiasis to complete the survey. We 
collected demographic information, including the location of practice (city), self-reported endourology fellowship training and self-reported access to SWL (either by referral or on site access). We also gathered self-reported descriptions of "academic" versus "community" practice and the existence of regionalized, priority surgical programs (such as neurosurgery, cardiac surgery, trauma, and/or vascular surgery) in the urologist's local hospital. The survey presented case scenarios focusing on the treatment modalities preferred for proximal ureteric, distal ureteric and intra-renal calculi. For ureteric stones, the index case was a 40-year-old, otherwise healthy woman presenting to the emergency department with right renal colic (no fever, no pyuria), found to have a radio-opaque (seen on both computed tomography $[\mathrm{CT}]$ and $\mathrm{CT}$ and a kidney, ureter and bladder x-ray [KUB]) distal or proximal (adjacent to transverse process of L3) ureteric calculus of varying size $(4,8$ and $14 \mathrm{~mm})$. For nephrolithiasis, the index case was a 40-year-old otherwise healthy woman presenting to an office setting with an incidentally diagnosed and asymptomatic (no urinary tract infection or flank pain) radio-opaque right upper calyceal stone (seen on both $\mathrm{CT}$ and KUB without accompany hydronephrosis) of varying size (3, 8 and $14 \mathrm{~mm}$ ). Other renal stone cases included an asymptomatic 22-mm renal pelvic stone with no hydronephrosis and an asymptomatic $15-\mathrm{mm}$ lower calyceal stone with no associated hydronephrosis. Respondents were asked to select the actual treatment modality they use in clinical practice and up to two treatments which they felt were "ideal" modalities.

Statistical analysis was performed with SAS Version 9.2 (SAS Institute Inc., Cary, NC). Respondents' choice of actual and ideal treatment was compared in a descriptive format as more than one response to ideal treatment was possible. Multivariate logistic regression modelling was used to assess predictors of treatment choice incorporating SWL access, practice in an academic setting, or alongside a priority surgical program, and endourology training into the model. A $p$-value $<0.05$ was considered statistically significant for all analyses.

\begin{tabular}{ll}
\hline $\begin{array}{l}\text { Table 1. Demographic characteristics of survey } \\
\text { respondents }\end{array}$ \\
\hline Characteristic & $\mathbf{N}(\%)$ \\
\hline Province of practice & $50(38)$ \\
Ontario & $22(17)$ \\
Quebec & $16(12)$ \\
British Columbia & $16(12)$ \\
Alberta & $16(12)$ \\
Maritimes & $5(4)$ \\
Saskatchewan & $5(4)$ \\
Manitoba & $1(1)$ \\
\hline Newfoundland & $22(17)$ \\
\hline Fellowship trained in endourology/stone disease & $100(76)$ \\
\hline Access to SWL & $55(42)$ \\
\hline Hospital type & $76(58)$ \\
\hline Academic & $86(66)$ \\
\hline Community & \\
\hline Privileges at hospital with regionalized services \\
(e.g., trauma, vascular, neurosurgery, etc.) \\
\hline SWL: shock wave lithotripsy.
\end{tabular}

\section{Results}

There were a total of 131 responses (113 English and 18 French surveys), yielding a $36 \%$ response rate. We tallied the demographic characteristics of respondents (Table 1).

Actual and ideal treatment choices for intra-renal (Table 2), distal (Table 3) and proximal ureteric stones (Table 4) were noted. In our multivariate analysis, none of the variables that were collected predicted the use of a specific modality for distal ureteric calculi. The use of ureteroscopy for treating proximal ureteric stones was less likely if respondents were at an institution with regionalized surgical services $(4-\mathrm{mm}$ stone: OR 0.10; 95\% Cl: 0.01- 0.76, $p=0.03$ and 8-mm stone: OR 0.33; 95\% Cl: 0.13-0.83, $p=0.02$ ). Shock wave lithotripsy was more likely to be used on proximal ureteric stones by those at an academic hospital (8-mm stone: OR $4.12 ; 95 \% \mathrm{Cl}: 1.70-9.98, p=0.002$ and $14-\mathrm{mm}$ stone: $\mathrm{OR}$ $3.87 ; 95 \% \mathrm{Cl}: 1.59-9.44, p=0.003)$. Moreover, those at an

\section{Table 2. Actual and ideal treatment modalities for distal ureteric stones (percentage)}

\begin{tabular}{|c|c|c|c|c|c|c|c|c|c|c|}
\hline $\begin{array}{l}\text { Stone } \\
\text { size } \\
(\mathrm{mm})\end{array}$ & & $\begin{array}{c}\text { Open } \\
\text { uretero- } \\
\text { lithotomy }\end{array}$ & PCNL & $\begin{array}{c}\text { URS and } \\
\text { intra-corporeal } \\
\text { lithotripsy/ } \\
\text { stone retrieval }\end{array}$ & $\begin{array}{l}\text { Extra- } \\
\text { corporeal } \\
\text { SWL } \\
\end{array}$ & $\begin{array}{l}\text { Cystoscopy } \\
\text { and ureteric } \\
\text { stent insertion } \\
\text { under general } \\
\text { anesthetic }\end{array}$ & $\begin{array}{c}\text { Cystoscopy and } \\
\text { ureteric stent } \\
\text { insertion under } \\
\text { local anesthetic }\end{array}$ & $\begin{array}{l}\text { Analgesia, } \\
\text { medical } \\
\text { expulsive } \\
\text { therapy, } \\
\text { and close } \\
\text { follow-up }\end{array}$ & $\begin{array}{l}\text { Analgesia } \\
\text { and close } \\
\text { follow-up }\end{array}$ & Total (n) \\
\hline \multirow{2}{*}{4} & Actual & 0 & 0 & 5.1 & 1.4 & 0 & 0 & 76.6 & 16.8 & 137 \\
\hline & Ideal & 0 & 0 & 17.4 & 1.5 & 0.5 & 0.5 & 55.4 & 24.6 & 195 \\
\hline \multirow{2}{*}{8} & Actual & 0 & 0 & 57.5 & 7.5 & 2.2 & 2.2 & 27.6 & 3.0 & 134 \\
\hline & Ideal & 0 & 0 & 54.3 & 14.6 & 1.5 & 2.0 & 22.1 & 5.5 & 199 \\
\hline \multirow{2}{*}{14} & Actual & 0 & 0.8 & 80.3 & 6.1 & 3.8 & 5.3 & 3.0 & 0.8 & 132 \\
\hline & Ideal & 0 & 0.5 & 65.9 & 19.8 & 5.5 & 3.3 & 4.4 & 0.5 & 182 \\
\hline
\end{tabular}




\begin{tabular}{|c|c|c|c|c|c|c|c|c|c|c|}
\hline $\begin{array}{l}\text { Stone } \\
\text { size } \\
(\mathrm{mm})\end{array}$ & & $\begin{array}{c}\text { Open } \\
\text { uretero- } \\
\text { lithotomy }\end{array}$ & PCNL & $\begin{array}{l}\text { URS and intra- } \\
\text { corporeal } \\
\text { lithotripsy/ } \\
\text { stone retrieval }\end{array}$ & $\begin{array}{l}\text { Extra- } \\
\text { corporeal } \\
\text { SWL } \\
\end{array}$ & $\begin{array}{c}\text { Cystoscopy } \\
\text { and ureteric } \\
\text { stent insertion } \\
\text { under general } \\
\text { anesthetic } \\
\end{array}$ & $\begin{array}{c}\text { Cystoscopy and } \\
\text { ureteric stent } \\
\text { insertion under } \\
\text { local anesthetic }\end{array}$ & $\begin{array}{l}\text { Analgesia, } \\
\text { medical } \\
\text { expulsive } \\
\text { therapy, } \\
\text { and close } \\
\text { follow-up }\end{array}$ & $\begin{array}{l}\text { Analgesia } \\
\text { and close } \\
\text { follow-up }\end{array}$ & Total (n) \\
\hline \multirow{2}{*}{4} & Actual & 0 & 0 & 6.0 & 9.7 & 1.5 & 0.7 & 60.4 & 21.6 & 134 \\
\hline & Ideal & 0 & 0 & 14.8 & 13.2 & 3.2 & 1.6 & 45.5 & 21.7 & 189 \\
\hline \multirow{2}{*}{8} & Actual & 0 & 0 & 28.2 & 34.4 & 9.2 & 5.3 & 20.6 & 2.3 & 131 \\
\hline & Ideal & 0 & 0.5 & 34.5 & 41.7 & 7.8 & 4.9 & 8.3 & 2.4 & 206 \\
\hline \multirow{2}{*}{14} & Actual & 0 & 1.5 & 38.8 & 36.6 & 15.7 & 5.2 & 2.2 & 0 & 134 \\
\hline & Ideal & 0 & 2.4 & 41.0 & 40.0 & 11.9 & 2.9 & 1.4 & 0.5 & 210 \\
\hline
\end{tabular}

PCNL: percutaneous nephrolithotomy; SWL: shock wave lithotripsy; URS: ureteroscopy.

academic institution were less likely to perform ureteroscopy for upper calyceal stones $(8-\mathrm{mm}$ stone: $\mathrm{OR} 0.10 ; 95 \% \mathrm{Cl}$ : $0.01-0.91, p=0.04 ; 14-\mathrm{mm}$ stone: OR $0.18 ; 95 \% \mathrm{Cl}: 0.03-$ $0.96, p=0.0449)$. In the treatment of lower calyceal stones, respondents at academic institutions were less likely to perform ureteroscopy (OR 0.11; 95\% Cl: 0.02-0.62, $p=0.01$ ).

Those with endourology training were more likely to perform PCNL for a 14-mm upper calyceal stone (OR 6.29; 95\% Cl: 1.21-32.76, $p=0.03)$, a 22-mm renal pelvic stone (OR 4.02; 95\% Cl: 1.09-14.87, $p=0.04$ ) or $15-\mathrm{mm}$ lower calyceal stone (OR 3.40; 95\% Cl: $1.21-9.51, p=0.02$ ). Interestingly, those with endourology training were less likely to treat a $15-\mathrm{mm}$ lower calyceal stone with SWL without a stent (OR 0.18; 95\% Cl: 0.04-0.85, $p=0.03)$.

\section{Discussion}

This study demonstrates that, while the management of ureteric and intra-renal calculi by Canadian urologists is highly varied, the overall treatment patterns fit with published guidelines. ${ }^{2,5}$ Respondents' selection of treatment modality under ideal circumstances was compared to actual practice to identify discrepancies. There are numerous drivers of disparity between ideal and actual scenarios; however, we sought to probe the impact of operating room access in particular. Public and political interest have focused on improving access and wait times for surgery in Canada, specifically in oncologic procedures, including those in urology. ${ }^{6}$ In our analysis, we collected covariates which may serve as a proxy to increased wait times: practice in an academic setting and the concomitant presence of regionalized, priority surgical services. There is evidence that academic and higher volume centres have a trend toward increased wait times for urologic surgery, as well as other disciplines; however, this trend is not always consistent. ${ }^{7-9}$

The use of ureteroscopy for treating a 4-mm distal ureteral stone was selected threefold in the ideal setting than actual practice. This trend may represent a trial of conservative management, prior to embarking on ureteroscopy. For larger distal ureteric stones, there was also a two-threefold greater selection of SWL in the ideal setting compared to actual practice. In our multivariate model, none of the variables were predictors of SWL use, including access. Ureteroscopy for a 4-mm proximal ureteral stone was selected twofold in the ideal setting. In our multivariate analysis, we found that Canadian urologists were less likely to use ureteroscopy if they were at a centre with regionalized services.

Major disparities were not identified between actual and ideal scenarios as highlighted with the responses seen for most proximal ureteral stones as well as upper or lower calyceal stones. There is concordance between what respondents felt was ideal and actual clinical practice, in keeping with published guidelines that outline more than one treatment option as reasonable alternatives for each of the stone scenarios included in the survey.

Our multivariate analysis identified some potentially important drivers of treatment modality. Those at academic centres were less likely to do ureteroscopy for 8- to 14-mm upper calyceal stones or for a lower calyceal stone. In addition, urologists at academic centres were more likely to use SWL for the treatment of 8- or 14-mm proximal ureteral stones. These findings may be explained by the perception of easier access to lithotripters that are largely located at academic teaching hospitals in Canada.

Our analysis indicated a marked disparity in the treatment of large renal pelvic stones: $19 \%$ of respondents reported using SWL with a ureteral stent in place in actual practice, but none felt this should be done in ideal circumstances in favour of ureteroscopy or PCNL. Endourology training was a strong predictor for using PCNL, not only for renal pelvic stones, but also for a large lower calyceal stone. Lastly, endourology training was seen to predict management decisions for which there is emerging or new evidence, such as stenting prophylatically prior to SWL of stones lager than $1.5 \mathrm{~cm}$, particularly lower calyceal stones.

This is a cross sectional study using a descriptive approach of the patterns of practice in Canada to identify discrepancies between ideal and actual practice as it pertains to urolithia- 


\begin{tabular}{|c|c|c|c|c|c|c|c|c|c|}
\hline $\begin{array}{l}\text { Stone size } \\
\text { (mm) and } \\
\text { location }\end{array}$ & & $\begin{array}{l}\text { Open nephro } \\
\text { lithotomy }\end{array}$ & PCNL & $\begin{array}{l}\text { URS and } \\
\text { intra- } \\
\text { corporeal } \\
\text { lithotripsy/ } \\
\text { stone } \\
\text { retrieval }\end{array}$ & $\begin{array}{l}\text { Extra- } \\
\text { corporeal } \\
\text { SWL with a } \\
\text { ureteric stent } \\
\text { in place }\end{array}$ & $\begin{array}{l}\text { Extra- } \\
\text { corporeal } \\
\text { SWL }\end{array}$ & $\begin{array}{l}\text { Medical } \\
\text { expulsive } \\
\text { therapy and } \\
\text { follow-up } \\
\text { imaging }\end{array}$ & $\begin{array}{c}\text { Follow-up } \\
\text { imaging only }\end{array}$ & Total (n) \\
\hline \multirow{2}{*}{$\begin{array}{l}3 \text { (upper } \\
\text { calyx) }\end{array}$} & Actual & 0 & 0 & 0 & 0 & 2.4 & 1.6 & 96.0 & 125 \\
\hline & Ideal & 0 & 0 & 0.7 & 0 & 9.9 & 3.5 & 86.0 & 143 \\
\hline \multirow{2}{*}{$\begin{array}{c}8 \text { (upper } \\
\text { calyx) }\end{array}$} & Actual & 0 & 0 & 7.9 & 3.1 & 52.0 & 0.8 & 3.6 & 127 \\
\hline & Ideal & 0 & 0 & 10.8 & 3.8 & 47.0 & 1.6 & 3.7 & 185 \\
\hline \multirow{2}{*}{$\begin{array}{c}14 \text { (upper } \\
\text { calyx) }\end{array}$} & Actual & 0 & 6.3 & 10.3 & 15.1 & 47.6 & 0 & 20.6 & 126 \\
\hline & Ideal & 0 & 10.0 & 15.3 & 17.4 & 40 & 0 & 17.4 & 190 \\
\hline \multirow{2}{*}{$\begin{array}{c}22 \text { (renal } \\
\text { pelvis) }\end{array}$} & Actual & 0.8 & 60.8 & 5.4 & 19.2 & 7.7 & 0 & 5.4 & 130 \\
\hline & Ideal & 0.7 & 69.4 & 12.5 & 0 & 10.4 & 0 & 6.9 & 144 \\
\hline \multirow{2}{*}{$\begin{array}{l}15 \text { (lower } \\
\text { calyx) }\end{array}$} & Actual & 0 & 24.2 & 10.2 & 10.9 & 28.1 & 0 & 26.6 & 128 \\
\hline & Ideal & 0 & 29.9 & 15.7 & 13.2 & 21.8 & 0.5 & 18.8 & 197 \\
\hline
\end{tabular}

PCNL: percutaneous nephrolithotomy; SWL: shock wave lithotripsy; URS: ureteroscopy.

sis. While our response rate was in line with similar studies, ${ }^{3}$ it should be noted that only CUA members, and moreover only those with registered e-mail access, participated in this survey. Our results did contain rare outliers, such as the selection of open nephrolithotomy for a renal pelvic stone, which may represent an error by the respondent or actual practice not in keeping with the standard of care. Congruency analysis to describe the percentage of times that respondents were actually doing what they recommended was considered; however, we elected against this approach as it ignores the fact that more than one modality might be equally acceptable as the ideal treatment. The strength of this study lies in the fact that beyond describing practice patterns, it seeks to suggest potential explanations for patterns observed by way of identifying disparities between ideal and actual situations and use of multivariable analysis.

The decision process in selecting a treatment modality is one that is complex and involves stone, patient, surgeon and system factors. We attempted to simplify this with clear scenarios and a single option for treatment decision. In reality, the process involves patient nuances and many other variables, including infection and situations of failed conservative management. In addressing decision analysis and the influence of operating room and resource accessibility, future research should include interrogating hospital databases, defining wait times and accessibility concerns in stone surgery and addressing potential inciting factors, such as hospital volume, more robustly.

\section{Interpretation}

CUA members' practices in the treatment of urinary lithiasis are in keeping with published guidelines. Our work suggests future research should address issues of operating room accessibility and wait times which may influence treatment decisions.

Acknowledgements: The authors would like to thank Richard Bolton of the CUA for facilitating survey recruitment.

Competing interests: None declared.

This paper has been peer-reviewed.

\section{References}

1. Seitz C, Liatsikos E, Porpiglia F, et al. Medical therapy to facilitate the passage of stones: what is the evidence? Eur Urol 2009;56:455-71.

2. Tiselius HG, Ackermann D, Alken P, et al. Guidelines on urolithiasis. Eur Urol 2001;40:362-71.

3. Bandi $G$, Best SL, Nakada SY. Current practice patterns in the management of upper urinary tract calculi in the north central United States. J Endourol 2008;22:631-6.

4. Hollowell CM, Patel RV, Bales GT, et al. Internet and postal survey of endourologic practice patterns among American urologists. J Urol 2000;163:1779-82.

5. Preminger $\mathrm{GM}$, Tiselius $\mathrm{HG}$, Assimos DG, et al. 2007 guideline for the management of ureteral calculi. J Urol 2007;178:2418-34.

6. Consensus document: recommendations for optimal surgical wait times for patients with urological malignancies. Can J Urol 2006;13(Suppl 3):62-4.

7. Siemens DR, Schulze KM, Mackillop WJ, et al. A population-based study of the waiting times for prostatectomy in Ontario. Can J Urol 2005;12:2568-74.

8. Bardell T, Belliveau P, Kong W, et al. Waiting times for cancer surgery in Ontario: 1984-2000. Clin Oncol (R Coll Radiol) 2006;18:401-9.

9. Simunovic M, Theriault ME, Paszat L, et al. Using administrative databases to measure waiting times for patients undergoing major cancer surgery in Ontario, 1993-2000. Can J Surg 2005;48:137-42.

Correspondence: Dr. Kenneth Pace, 61 Queen St. E, Suite 9-106Q, Toronto, ON M5C 2T2; fax: 416-867-3675; kenneth.pace@utoronto.ca 